\title{
Quase adulta, quase velha: por que antecipar as fases do ciclo vital? *
}

Russel Parry Scott ${ }^{1}$

SCOTT, P. R. Quasi adult, quasi old: why anticipate life cycle phases? Interface _ Comunic, Saúde, Educ, v.5, n.8, p.61-72, 2001.

By observing two different generations of women, one discovers that there is a phenomenon whereby the passage from one phase of the lifecycle to the following one may be anticipated. This phenomenon calls for interpretation. Many girls, for instance, get pregnant and, whether or not they get married, become mothers. Many women aged forty-five to fifty, on the other hand, join "senior citizen" groups. The interpretation that this essay proposes examines the consequences of: 1) demographic transition (and the resulting aging of the population), which lends particular visibility to these two generations; 2) exclusion from the job market; 3) government actions; 4) rising individualism; and 5) the logic of gender and generation relations in households. In order to explain the behavior of very nearly adult women and of women who are almost old, two groups that anticipate life cycle phases, one resorts to a combination of the above factors culminating in the establishment of a condition of generational borderlines, typical of rites of passage, and the construction of processes of de-ritualization and re-ritualization within current society.

KEYWORDS: life-cycle phases; generation relations; societies.

A partir de duas observações em gerações diferentes, identifica-se um fenômeno de antecipação da passagem pelas fases do ciclo vital que merece uma interpretação. Muitas jovens engravidam, casando ou não, e se tornam mães. Muitas mulheres na faixa de quarenta e cinco a cinqüenta anos ingressam em "grupos de idosos". A interpretação oferecida examina as conseqüências 1) da transição demográfica (e decorrente envelhecimento populacional) em dar visibilidade especial a estas gerações examinadas, 2) do mercado de trabalho que é excludente, 3) da atuação do Estado, 4) do individualismo crescente e 5) da lógica das relações de geração e gênero em grupos domésticos. Para explicar as ações das quase adultas e das quase velhas que antecipam as fases do ciclo vital, recorre-se à conjunção destes fatores que culmina numa criação de uma condição de liminaridade geracional, própria dos ritos de passagem, e na construção de processos de desritualização e re-ritualização da sociedade contemporânea.

PALAVRAS-CHAVE: fases do ciclo vital; relação entre gerações; sociedades.

\footnotetext{
* trabalho apresentado na reunião do REDOR em Teresina, 4 a 7 de julho de 2000

1 Professor do Departamento de Ciências Sociais, Programa de Pós-Graduação em Antropologia, Universidade Federal de Pernambuco, Coordenador do Fages, Núcleo de Família, Gênero e Sexualidade. <scott@hotlink.com.br>
} 
Ultimamente, o número de jovens grávidas tem chamado a atenção da sociedade. Cresce o número de programas de orientação para que as(os) jovens possam passar por esta experiência da melhor forma possível. No entanto, estes programas ainda atingem poucos na população jovem. Quando as jovens engravidam, aprontam-se para ouvir uma litania de acusações sobre irresponsabilidade, descuido, desleixo, falta de visão do futuro, desorganização etc. Parecem ter ofendido uma ordem ideal estabelecida de "aguardar o tempo certo" para ter um filho e para casar, seja qual for a ordem em que estes dois acontecimentos ocorrem. A convivência, observação e conversas mais prolongadas com estas mães muito jovens costumam revelar que ter este filho não foi nem tão impensado, nem tão fora dos padrões, quanto todas as acusações sugerem. O valor simbólico do filho é enorme, e a idéia de tê-lo muitas vezes foi "um acidente planejado". O 'ser irresponsável' foi justamente para ganhar responsabilidade. O filho é um futuro alcançável. É uma hora de testar a firmeza da organização da sua própria família. Parece que pode até valer a pena "antecipar" a passagem por este rito que marca a saída da infância $e$ juventude vigiadas e a entrada numa vida plena de adulta.

$\mathrm{Na}$ outra ponta da passagem pelas fases da vida, cresce o número de idosos que encontram amizade, solidariedade e direção na sua vida associando-se a "grupos de idosos", que, de fato, são predominantemente femininos. Esses grupos espantam muitos observadores quando verificam que um bom número das idosas "não são tão velhas assim". Essas "idosas jovens" são mães, são tias, são avós, mas muitas nem chegaram a cinqüenta anos. Estas idosas se alegram com a idéia de serem "crianças de novo", de brincar, de dançar, de passear, de estar aproveitando cada dia, de namorar. Enfim, tal procedimento fica muito distante daquela visão de idosas doentes internadas em asilos, eternamente engajadas em conversas sobre as dores que sentem e os remédios que precisam. Passar para um grupo de idosos pode ser uma forma de recriar laços de solidariedade, sem que isso implique na negação total dos laços familiares e de parentesco, no qual a participação não é um "fardo de responsabilidade". Com toda a significação pessimista que acompanha o avanço na idade, admitir que já se é idosa pode também trazer muitos benefícios. Novamente, parece valer a pena antecipar a passagem pelas fases do ciclo vital.

É sobre estas observações de antecipação da passagem pelas fases do ciclo vital em duas gerações distintas que gostaria de comentar, na esperança de que as idéias contribuam para uma melhor compreensão do fenômeno. A apresentação das idéias será bastante compartimentalizada, justamente para poder isolar elementos diferentes que confluem para a criação deste cenário. Para dar corpo e contextualização às idéias, recorre-se a exemplos extraídos de experiências de pesquisa de campo entre grupos populares pernambucanos realizada por uma equipe do Núcleo de Família, Gênero e Sexualidade (FAGES) da Universidade Federal de Pernambuco, bem como do material publicado sobre idosos de Debert (1999) e Britto da Motta (1999). Finalmente, estas questões são associadas à literatura clássica antropológica sobre ritos de passagem e relações entre gerações. 


\section{Uma base etnográfica sobre jovens e idosos}

Uma ampla revisão da literatura sobre jovens e idosos para sustentar os comentários nos primeiros dois parágrafos seria muito valiosa e permitiria uma boa matização e contextualização que mostraria a enorme pluralidade $e$ complexidade nas quais ocorrem estes fenômenos (e outros que aparentam contradizê-los). Mas tal revisão foge do alcance deste artigo. A opção é de calcar as idéias em torno de observações de campo realizados durante a pesquisa "Saúde e Pobreza no Recife"(Scott 1996) e "Reprodução, Sexualidade e Programas de Saúde em Grupos Sociais Distintos em Pernambuco". Scott (2000), Butto e Silva (1999) e estudos recentes de Britto da Motta (1999) e Debert (1999), todos privilegiam grupos populares, embora Debert e Britto da Motta também discutam grupos en melhores condições econômicas.

No bairro do Ibura mães adolescentes são uma ocorrência freqüente, $e$ observamos várias famílias se reorganizando de acordo com esta condição das suas filhas. Além da cobrança de maior responsabilidade, houve vezes em que a própria gravidez instalava discussões sobre afiliação religiosa $e$ sobre os papéis maduros exigidos pela maternidade e pela paternidade. As conversas familiares sobre "moral", ou ainda melhor, as ações que encenavam o código moral familiar, foram postas a vista para a família, $e o$ resultado era o estabelecimento das relações familiares num novo patamar com uma aceitação diferente, mais plena, da filha, como adulta com responsabilidade própria.

Não foi diferente em São Domingos, no interior, onde Butto e Silva ouviram uma adolescente dizer:

\footnotetext{
${ }^{2}$ Dados levantados na pesquisa Gravidez e Juventude em São Domingos, Brejo da Madre de Deus, Pernambuco, Universidade Federal de Pernambuco/UFPE, 2000.
}

${ }^{3}$ Dados levantados na pesquisa Gravidez e Juventude em São Domingos, Brejo da Madre de Deus,

Pernambuco, UFPE, 2000.
Mãe? Quando eu perdi a virgindade eu não tava aqui, aí eu acho que ela queria que fosse assim, depois que eu arrumasse um marido, sabe? Ela dizia até assim: - Ó meu Deus, quando é que essa menina vai arranjar um marido para deixar de ser tão criança? Aí quando perdi eu não tava aqui não. Ai depois voltei, acho que já tava grávida. Tava com um mês. Ai eu fiquei aqui mais ela, ai ela me ensinou como era as coisas, ela me ensinava assim ${ }^{2}$.

A maturidade exige que "deixe de ser criança", mas o casar é mais ambíguo, pois ele pode também restringir uma liberdade que as filhas conseguem ganhar ficando na casa dos pais:

Primeiramente eu comecei a ter mais um pouco de liberdade. ... Não assim, porque antes para mim ir pra uma festa, sair, a minha mãe, meus pais eles só deixavam se eu fosse com alguém da família ou alguém maior, alguém de responsabilidade. Hoje algumas festas eu vou, sabe, tenho um pouco mais de liberdade, antes eles impediam um pouco, sabe? ${ }^{3}$ 
Os adolescentes enfrentam um sistema de atendimento à saúde no qual primeiro são acusados de irresponsáveis para depois serem alertados sobre os perigos e a causalidade econômica da gravidez precoce. Mas para eles, a situação é percebida mais como a busca de liberdade e autonomia dentro de tradições familiares, mesmo que seja (ou talvez em alguns casos, preferencialmente) sem casar e sem tolher a nova liberdade com responsabilidade (Butto e Silva 1999).

É curioso quanto o discurso dos idosos repete parte do dos adolescentes, ressaltando, novamente, a liberdade e a autonomia ${ }^{4}$. Liberdade que implica uma ressignificação do processo de envelhecer, muito bem descrita no livro de Debert (1999). Britto da Motta (1999) e Debert mostram que a procura pelas universidades da terceira idade (pequena pelos grupos populares que tiveram pouco acesso à educação formal) é majoritariamente por pessoas de faixas etárias abaixo de sessenta anos (até $80 \%$ num dos exemplos citados). É nos grupos de convivência que os idosos de camadas populares demonstram jovialidade, ou faceirice. Debert inicia um capítulo descritivo sobre esses grupos, centrado no SESC, na LBA e nas universidades da terceira idade, com a fala de um idoso:

Eu acho a terceira idade uma inovação, a melhor possível sobre o idoso. Foi a melhor possível porque deixa a gente assim, numa liberdade total, sabe? É uma gostosura. (Debert, 1999, p.144)

Britto da Motta (1999) centra seu trabalho no mesmo tipo de associações, dando maior ênfase aos grupos populares que à "faculdade da terceira idade". Assim diz uma senhora que percebe modificações em sua relação conjugal e em sua participação no grupo:

O tempo melhor é agora. No momento, porque quando eu trabalhava, não tinha liberdade. Agora eu saio com quem eu quero e volto a hora que eu quero. No início do casamento ele não gostava quando eu saía, hoje ele vê que preciso sair para me distrair, porque ele passa o dia trabalhando e eu fico sozinha em casa. (Britto da Motta 1999, p.83)

As conclusões de Britto da Motta, após uma extensa discussão de quatro grupos de convivência em contextos diferentes, são que esses grupos reforçam "a ampliação da sociabilidade, do lazer, da informação e do próprio prazer de viver" (1999, p.263), com uma repercussão mais forte nas mulheres que nos homens, que participam menos.

A reinvenção da velhice está associada a fatores muito complexos, bem analisados em Debert (1999), mas o que precisa ser enfatizado aqui é que essa reinvenção, na sua grande diversidade, deixa uma evidente valorização da "juventude" dos idosos, da sua ampliada sociabilidade e capacidade de consumo. Faz esta fase de vida se definir como "desejável" e não como "decadente" $e$ isso é fundamental para "jovens idosos" aspirarem a entrar numa categoria na qual podem negar uma identificação social negativa clássica que rapidamente se transforma.
${ }^{4}$ Conforme pesquisa de Scott, 1996. 


\section{A transição demográfica e a visibilidade das gerações nas pontas}

A queda de fecundidade que marcou a década de oitenta no Brasil trouxe consigo uma discussão sobre o envelhecimento populacional, uma decorrência óbvia do processo. Menos filhos por mulher tem implicações sérias sobre a vivência do ciclo vital, pois o período efetivo envolvido no processo de gravidez e criação de prole fica bem mais reduzido. Já foi muito evidenciado que a laqueadura de trompas, uma esterilização definitiva, é o procedimento mais usado por mulheres que já alcançaram o número de filhos desejados, com destaque notável para o Nordeste. A transição demográfica resultou numa mudança na distribuição da idade de parturientes. As mulheres mais novas são as mães de prole cada vez menos numerosa. Sem dúvida, este é um fenômeno mais importante no Brasil do que a internacionalmente badalada extensão da idade em que mulheres podem parir, que depende de intervenções médicas sofisticadas e caras. Se antes era bastante freqüente uma filha começar a parir antes que sua mãe tivesse encerrado sua carreira reprodutiva, hoje é bem menos. Mães que encerraram as suas carreiras reprodutivas vão olhar mais para as carreiras das suas filhas. Pesquisas recentes insistem que "adolescente engravidar" não é mais de que uma continuidade de um processo histórico bastante bem estabelecido. O fato de que as suas mães não estão engravidando mais que é o fenômeno novo. Assim, cria uma visibilidade "falsa" das jovens grávidas. Jovens, de fato, estão compondo proporções decrescentes da população total nas pirâmides etárias pós transição demográfica. Aliás, cada vez menos se pensa em "pirâmides" por causa do encolhimento da base. De repente, o que era costumeiro se torna um problema que precisa ser tratado por figuras responsabilizadas por apontar e administrar os rumos mais amplos da sociedade.

Mas não são somente as jovens parideiras que estão se tornando mais visíveis. Com menores taxas de fecundidade e uma melhora nas condições sanitárias do país, os idosos são aquela proporção pequena de população que está crescendo proporcionalmente mais rápido. É a condição inversa da população de jovens. Os idosos estão requerendo mais atenção para si mesmos, e a condição especial vivida por eles está merecendo destaque em todas as esferas - família, educação, trabalho, previdência, lazer. É uma faixa de população que cresce e que apresenta novas demandas como foram demonstradas na discussão dos grupos de idosos acima.

São duas gerações que sofrem pressões demográficas diferentes, mas que estão se tornando mais visíveis devido à transição demográfica.

\section{O estreitamento do mercado de trabalho}

Seja jovem ou seja idoso, o mercado de trabalho não está favorável ao trabalhador. Índices de desemprego que já eram altos alcançam níveis inusitados. Se "o trabalho dignifica o homem", não há boa perspectiva para a população encontrar formas seguras de adquirir sua dignidade. Há sempre denúncias contra o trabalho infantil, especialmente porque isto ocorre de forma mascarada na produtividade e remuneração de adultos. O próprio 
encontrar trabalho quando muito jovem é outra forma de "antecipar a passagem pelas fases do ciclo vital", e é comum ouvir trabalhadores comentarem que "não tiveram infância". Quando o caminho da identidade adulta pelo trabalho for dificultado, há outras formas de mostrar que se está alcançando a "respeitabilidade" do adulto - e formar família para homens, e, sobretudo, para mulheres, é uma delas. Nesta hora "família" se define mais como "ter um filho" de que "casar" ou "morar junto."

Os que de fato estão trabalhando carregam os seus dependentes, jovens $e$ idosos. Mas há pelo menos uma diferença séria nesta confrontação de gerações pela distribuição dos resultados do trabalho. É o que Meillasoux (1979) descreveu como as estruturas "alimentares" do parentesco, onde os pré-produtivos são potencializados como trabalhadores capazes de sustentar os seus pais no futuro, e os pós-produtivos são os que têm, por merecimento de trabalho já feito, direito a serem sustentados pelos que estão trabalhando. Mas quando a saída do mercado de trabalho é precoce e a esperança de vida está aumentando, o período pós-produtivo se amplia. Isso cria uma necessidade de re-identificação deste período através da descoberta de uma série de atividades que valorizam o idoso. Embora isto seja mais marcante para os homens, por eles construírem as suas identidades sobre a capacidade de serem "provedores", a ampliação da participação das mulheres no mercado de trabalho na segunda metade do século vinte contribuiu muito para que elas, também, vivessem situações semelhantes. $E$, evidentemente, a própria questão da longevidade maior das mulheres faz com que a fase dos idosos seja cada vez mais feminilizada. Em reconhecimento à complementariedade englobada pela divisão de trabalho na família, a legislação favorece que muitas viúvas mantenham o direito a pensões e rendas que representam o reconhecimento da manutenção do seu direito como pós-produtivo. Recebendo pensões, não há porque não complementar com outros ganhos, mas estes nem sempre são fáceis de encontrar. Os grupos de idosos são, primeiramente, redes de ampliação de sociabilidade como foi discutido acima, e não são, fundamentalmente, redes de alcançar rendas adicionais, mas há envolvimento em artesanato, cozinha $e$ outras atividades que possam chegar a complementar renda.

De qualquer jeito, um mercado de trabalho mais estreito cria exigências especiais tanto sobre os jovens quanto sobre os idosos, no sentido de favorecer a procura de formas adicionais, que não o trabalho, pelas quais podem se identificar como pertencentes a um segmento geracional específico da sociedade mais ampla.

\section{O Estado e a identidade da população}

A ambigüidade do papel do Estado está, sobremaneira, conhecida. Ele legitima as ações dos atores da sociedade, legislando e fiscalizando de um modo que possa reforçar as estruturas de poder vigentes, ao mesmo tempo em que ele assume o papel de redistribuidor de riqueza, vigilante às necessidades daqueles cidadãos que, sem a intervenção do Estado, seriam ainda mais "excluídos". Assim, os aparelhos institucionais do Estado necessariamente se revestem, parcialmente, de uma roupagem de 
redistribuidores e de feitores de justiça. A identificação de populações específicas como "alvos" da atuação é parte do planejamento para o fortalecimento da sociedade vigente, ao mesmo tempo em que é um ato que facilita o aporte de recursos e de serviços para lidar com os problemas daquela população específica. Na busca de parceiros para elaborar estratégias de ação nestes setores, o Estado promove a junção de esforços entre organizações não-governamentais, associações de moradores e alas de serviços sociais do próprio governo. Tanto para os jovens, quanto para os idosos, isto cria uma multiplicidade e complexidade de instituições e ações que podem ser acionadas para dar apoio ao Estado (Programas de Saúde, SESC, LBA etc.). Simultaneamente, a regra é que, para a maioria de jovens e de idosos, há, de fato, poucas oportunidades reais de se engajar em atividades promovidas, direta ou indiretamente, pelo Estado, que sejam especialmente dirigidas a eles. Pelos meios de comunicação há possibilidade de ver muitas destas ações, às vezes criando uma aparência de maior cobertura do que o Estado, de fato, está conseguindo realizar. Os próprios parceiros do governo nestas atividades às vezes são os mais assíduos nos esforços de divulgação das atividades, pois isto é necessário para a sobrevivência destas instituições, $e$, torna-se um veículo para aparentar um maior número de ações em andamento.

Assim, os jovens contam com programas governamentais como a PROSAD, programa de saúde do adolescente, programas de capacitação para o trabalho, de educação, de bolsas escolares, de erradicação de trabalho infantil, de tirar meninos e meninas da rua, de evitar a prostituição juvenil, de proteção contra o uso de drogas etc. Para falar novamente em "visibilidade", cria um espaço cuja importância é constantemente reforçada, em que se evidencia a juventude como um setor que "preocupa o país," pois enfrenta dificuldades grandes e merece ações especiais se estes jovens vão se tornar os adultos de amanhã se desfrutando de um futuro melhor. É a criação da imagem e a realização de um número suficiente de ações concretas para que um Estado omisso se pareça atuante, que faz com que, cada vez mais, evidenciem-se os jovens na sociedade.

Os idosos suscitam outro tipo de preocupação para o Estado. Maior longevidade é uma indicação de saúde, e o país sempre batalha para ser incluído entre os países cujos índices estão melhorando. Para o Brasil, mesmo que não tenha alcançado os níveis almejados, tem havido um incremento regular na longevidade. Mas como a recente modificação do critério de ranking da Organização Mundial de Saúde, tomando em conta a variável "qualidade de vida" e não apenas o número de anos, o Brasil se descobre em plena queda neste ranking ( $125^{\circ}$ lugar). O importante é insistir que o Estado está atento a este problema e está promovendo uma melhora na vida dos idosos. Quem participa de pesquisas sobre idosos nota que, nas associações e grupos, uma enorme ênfase é dada ao lado lúdico. Estas associações, às vezes, estão também estreitamente relacionadas à resolução de problemas com a documentação necessária para garantir os direitos de aposentadorias, benefícios e tratamento de saúde, mas na insistência em ressignificar a fase da "velhice" para que ela tenha um aspecto mais positivo - a boa idade, a terceira idade, os anos de ouro etc., como mostram de 
maneira clara Debert (1999) e Britto da Motta (1999). Se é caro manter os idosos da forma que os cofres do Estado se organizam, e assim, eles dificultam a consecução das metas do Estado, também é importante demonstrar o quanto se está fazendo para tornar esta fase de vida melhor. Debert ainda ressalta que há um mercado consumidor a ser ganho neste tipo de ressignificação. Podemos insistir que, com esta faceta adicional, a ambigüidade da ação do Estado fica ainda mais evidente.

O crescente individualismo $e$ autoridade, afeto e autonomia: vínculos entre gerações e gênero

A fragmentação de redes de parentesco e de vizinhança anteriormente mais solidárias vem sendo progressivamente mais evidenciada em face do crescente individualismo na sociedade moderna. O individualismo favorece o desenvolvimento de valores que demonstra o que as pessoas conseguem através do seus próprios esforços, e não tanto por ser parte de algum grupo mais amplo que possa conferir a eles algum status especial. Segundo alguns autores, quando muito, este esforço é compartilhado por uma tribo - um grupo que se forma e mantém contatos de apoio mútuo, sem que sejam principalmente de parentesco ou vizinhança. Fatalmente, isto tem implicações extraordinariamente importantes tanto para os jovens, quanto para os idosos.

Para os jovens, que vêm experimentando dependência doméstica desde a sua nascença, sair do jugo da autoridade parental é uma declaração de autonomia $e$ individualidade. É a negação da inclusão no domínio parental que constitui uma das esferas mais importantes para o reforço do "individualismo". Ou seja, para as jovens, fica assim: "eu posso porque a decisão é minha, o corpo é meu e o filho será meu”. Os pais não recomendam que as filhas engravidem cedo - assim, o ato de engravidar raramente tem qualquer carimbo de "encomenda paterna" (em contraste, este carimbo é um dos aspectos evidentes no casamento formal, levando à pergunta imediata - quando pretende ter o filho?), mas também há amplas evidências de que é mais freqüente reabsorver positivamente a jovem, ou o jovem casal, no grupo familiar que inclui os pais, novos avôs" Assim, as filhas, $e$ os filhos, têm uma boa possibilidade de reconquistar uma posição de respeito e autoridade dentro do grupo familiar mais amplo (sendo coresidente ou não). O afeto e a responsabilidade, internos ao grupo de parentesco, sobrepõem-se à declaração da individualidade dos jovens, englobando-a aos atos esperados.

$O$ individualismo também se manifesta entre os idosos. Os padrões residenciais de países centrais incluem muitos idosos que residem sozinhos, e no Brasil, apesar da tradição de absorção e inclusão em famílias extensas co-residenciais, está aumentando o número de idosos que moram sozinhos. Como Goldani (1993) mostrou, quando pais relativamente novos, com as suas carreiras reprodutivas encerradas, alcançam a fase no seu ciclo doméstico de ver os filhos saírem para residir sós ou casar, iniciam um período muito mais longo que antigamente, de estarem morando como um casal independente. Mesmo que tenham a opção de incorporar netos ao seu 
convívio, é cada vez mais freqüente isto ser feito como um apoio temporário e prazeroso - é aquilo que é sempre ouvido: "Adoro os meus netos, porque quando canso deles voltam para a casa dos seus pais", ou "Eu tenho a minha vida, e quando quero, vejo os netos". Quer dizer, continua-se o afeto, continua-se a autoridade, mas diminui-se a responsabilidade cotidiana, $e$ amplia-se a cobrança que os próprios idosos fazem sobre sua capacidade de ter prazer na vida cotidiana. É nesta hora que os grupos de idosos servem muito bem, pois criam uma solidariedade de interesses comuns de pessoas que podem valorizar a importância das suas relações familiares, sempre integrando-as nas conversas, mas que não sofram as cobranças das obrigações familiares durante o convívio do grupo. Britto da Motta conclui que o "morar só" é percebido como uma fonte de prazer e não de solidão pela maioria dos idosos entrevistados por ela (1999). Não é raro que os pesquisadores comentem a livre referência a assuntos como sexualidade (muito reprimido no contexto familiar), quando reinicia-se o processo de namoros, enfim, um ambiente no qual os idosos "se soltam" mais, conseguindo se identificar como indivíduos que têm suas próprias vidas a viver e que já pagaram suas "dívidas" à sociedade.

\section{Liminaridade e a desritualização/re-ritualização da sociedade}

Afinal, o que está unificando as duas experiências descritas no início do trabalho: a adolescente grávida, e a participante jovem de um grupo de idosos? Recuperando e conjugando os elementos discutidos até agora, é interessante unificá-los com referência à literatura antropológica clássica sobre ritos de passagem.

Ao discutir o processo de demarcação social dos ciclos vitais individuais, Van Gennep (1972) frisou que há certos momentos em que se ritualiza uma transformação na identidade social da pessoa como fazendo parte de modificações que ocorrem na inserção destas pessoas em novas categorias comuns na sociedade. Os momentos críticos que ele realça, e denomina de ritos de passagem, são o nascimento, a puberdade, o casamento e a morte. Cada um destes ritos é composto, sucessivamente, por um período de separação da identidade social anterior; um período de transição entre identidade sociais, e, finalmente, um período de integração na nova identidade social. Por exemplo, os ritos de puberdade teriam elementos que marcam a saída da infância, outros que marcam a ambigüidade do novo papel de não mais criança, mas ainda não adulto, e finalmente, outros de plena integração na vida adulta. De forma semelhante, o casamento envolve ritos que simbolizam a saída do estado de 'solteirice', outros, cerimonializados, que simbolizam a transição; $e$ ainda outros que mostram a chegada ao estado de casado com todas as responsabilidades de pertencimento ao grupo que a plenitude da passagem implica. Para o nosso argumento aqui, é importante frisar bem o significado do estado de liminaridade, que foi muito estudado por Victor Turner (1967) e constrói-se sobre as idéias da fase de transição, da fase "liminar" de Van Gennep. A liminaridade descreve uma condição social na qual a identidade passa mais 
pela questão de negação que de afirmação. Ou seja, é a condição de "não ser" alguma coisa, de estar suspenso entre identidades sociais de que um pertencer está no passado, e outro pertencer ainda está no porvir.

É importante ressaltar que as advertências de Debert (2000, parte I), que realiza uma importante revisão da literatura sobre a pluralidade da vivência do curso da vida, envolvendo questões que vão além da idade, incluindo maturidade, gerações e ordem de nascimento, de que podemos confundir questões de idade com todas estas outras esferas. Nem sempre a idade cronológica é a chave para a compreensão do fenômeno sob investigação.

Assim, os conteúdos do pertencimento a fases distintas precisa ser entendida como algo extraordinariamente variável de acordo com classes $e$ questionamentos diferentes. Jovem e idoso, assim, são categorias que recebem qualificações que precisam ser bem entendidas de acordo com todas estas questões nos contextos concretos de investigação em que são observadas e interpretadas.

A combinação dos fatores descritos neste trabalho demonstra que, socialmente, as jovens que engravidam e as participantes "jovens" de grupos de idosos, sobretudo nos grupos populares enfatizadas, estão em fases do ciclo vital marcadas pela liminaridade, particularmente exacerbadas pelas condições na sociedade contemporânea. Pode-se assim resumir como é criada a liminaridade de cada fase, e ver como a ação focalizada promove a saída da liminaridade e a integração a uma nova identidade social.

A jovem que engravida está deixando uma fase de dependência acentuada dos pais. Tendo um filho, ela ganha mais visibilidade, o que em gerações anteriores, por causa da transição demográfica, torna a atividade reprodutiva da geração mais jovem ainda mais visível. Ela ocupa uma fase de "reprodutora" que a sua mãe, geralmente, já abandonara por esterilização. O estado liminar, no qual ela não se sente mais pertencente à categoria de "criança", é reconhecível no início jovem da vida sexual e no mercado de trabalho que a explora, mas apresenta pouca oportunidade para sua afirmação de autonomia. Uma vez grávida e mãe, o Estado problematiza, mesmo fracamente, a sua situação com uma diversidade de programas, e a afirmação da sua individualidade e da força potencial da sua integração no grupo familiar está posta a teste com a reação dos pais à sua autonomia, à gravidez e ao nascimento do filho. A ambigüidade de ser jovem, mas com poucas oportunidades de estudo e com cobrança sobre a participação no orçamento familiar e vigilância sobre a sua atividade sexual, faz com que a passagem para ser mãe possa denotar, para ela, uma saída desta liminaridade (não mais criança, ainda não adulta) e um ingresso numa fase de jovem adulta. Inclusive a sua participação no rito do "nascimento" como responsável pelo filho, reforça ainda mais este ingresso numa nova "identidade social". Numa vida marcada por poucos "ritos" formais de passagem, o 'ser mãe' fornece uma re-ritualização da passagem para o status de adulta.

A passagem para um grupo de idosos é um processo menos ritualizado. As pessoas costumam pensar que os outros vão reivindicar serem tratados como "ainda jovens" mais de que como "já idosos" pelo menos quando a idade não confere regularmente status. O que é que faz com que as pessoas 
ingressem cedo nos grupos de idosos, então? Importantíssimo é o fato que o processo de ressignificação da velhice a joga (não sem ambigüidades) exatamente na categoria de "juventude reforçada" (novamente relembro os argumentos de Debert, 1999). Especialmente no caso de grupos populares, os mesmos processos que influenciam as jovens trabalharem para fazer com que as adultas se sintam numa certa ambigüidade em relação aos seus papéis de provedoras e reprodutoras. Para as mulheres, com poucas oportunidades de ganhar dinheiro, muitas já esterilizadas, e com os filhos crescidos, já avós, sem maridos, algumas com benefícios e pensões vitalícias, não é nem a identidade de mãe, nem de trabalhadora, nem de dona de casa que a localiza com maior adequação na nova fase do ciclo vital no qual se está encontrando. Nas sociedades com longevidade aumentada e com reprodução encurtada (isto mais para as mulheres que para os homens), tem havido a criação de uma fase de liminaridade que exige a identificação mais clara desta nova fase importante no ciclo vital. Então, identificando-se quanto antes com o grupo de idosos, a adulta, mesmo ainda "jovem", mas já tendo experimentado todas aquelas experiências que constituem o cotidiano da vida como adulta, amplia oportunidades para solidariedade, para a redefinição de papéis, para o ingresso numa fase, com reforço de alguns programas estimulados pelo Estado e por outras entidades, que se caracteriza pelo "lúdico merecido", pelo "respeito", e pela "desobrigação", e ainda abre novos mercados para a sociedade de consumo. Está-se definindo um novo espaço no ciclo vital, tateando na descoberta de nomes adequados, mas desesperadamente procurando "ritualizá-lo" o suficiente para que se diferencie da "mesmice" da vida adulta atribulada e cheia de responsabilidades que todos conhecem. Se isto é um jogo de geração, de maturidade ou de idade certamente só pode ser respondida com a declaração de ser "uma combinação". Lembramos que, apesar das aparências, fases não são necessariamente seqüênciais, pois em cada fase e com cada assunto enfatizado, há a possibilidade dos atores ressaltarem marcas identificadoras distintas.

Antecipar a passagem pelas fases do ciclo vital, engravidando jovem ou ingressando jovem em grupos de idosos, não é um fenômeno casual ou excepcional, e sim, um fenômeno que as condições da sociedade contemporânea brasileira tem favorecido e, tudo indica, vai continuar favorecendo e procurando ressignificar e embaralhar de novo no curso da vida.

Referências bibliográficas

BRITTO DA MOTTA, A. Não está morto quem peleia: a pedagogia onesperada nos grupos de idosos. Salvador, 1999. Tese (PhD) Programa de Pós-Graduação em Educação, Universidade Federal da Bahia.

BUTTO, A., SILVA, J. M. Representações sociais da sexualidade e da reprodução na adolescência e os serviços de saúde em São Domingos, Brejo da Madre de Deus, Pernambuco. Rev. Anthropol., v.9 (Série Família e Gênero), p.86-97, 1999.

DEBERT, G. G. A reinvenção da velhice. São Paulo: EDUSP-FAPESP, 1999.

GOLDANI, A. M. As famílias no Brasil contemporâneo e o mito da desestruturação. Cad. PAGU, v.1, 
p.68-110, 1993.

MEILLASOUX, C. Mujeres, graneros y capitales: economía doméstica y capitalismo. México: Siglo XXI, 1977.

SCOTT, R. P. Saúde e pobreza no Recife: poder, gênero e representação de doenças no bairro do Ibura. Recife: Editora Universitária-UFPE-JICA, 1996.

SCOTT, R. P. Reprodução, sexualidade e programas de Saúde em grupos sociais distintos.

Relatório Final UFPE-CNPQ. Recife, 2000.

TURNER, V. The forest of symbols. Ithaca: Cornell University Press, 1967.

VAN GENNEP, A. Rites of passage. Chicago: University of Chicago, 1972.

SCOTT, P. R. Casi adulta, casi vieja:¿ por qué anticipar las fases del ciclo vital? Interface Comunic, Saúde, Educ, v.5, n.8, p.61-72, 2001.

Com base en dos observaciones en genaraciones diferentes, se identifica la anticipación del pasaje entre fases del ciclo vital que merecen interpretación. Muchas jóvenes se quedan embarazadas, y casando o no, se vuelven madres. Muchas mujeres entre cuarenta y cinco y cincuenta años ingresan en "grupos de ancianos". La interpretación ofrecida examina las consecuencias 1) de la transición demográfica (y el resultante envejecimiento populacional), en dar visibilidad especial a estas geraciones examinadas, 2) del mercado de trabajo excluyente, 3) de la acción del Estado, 4) del individualismo creciente y 5) de la lógica de las relaciones entre generación y género en grupos domésticos. Para explicar las acciones de las casi adultas y de las casi viejas que anticipan las fases del ciclo vital, se usa el conjunto de estos factores que culmina en la creación de una condición de liminaridad generacional, propia de los ritos de pasaje, y en la construcción de procesos de desritualización y reritualización de la sociedad contemporánea.

PALABRAS CLAVE: etapas del ciclo de vida; relación entre generaciones; sociedades
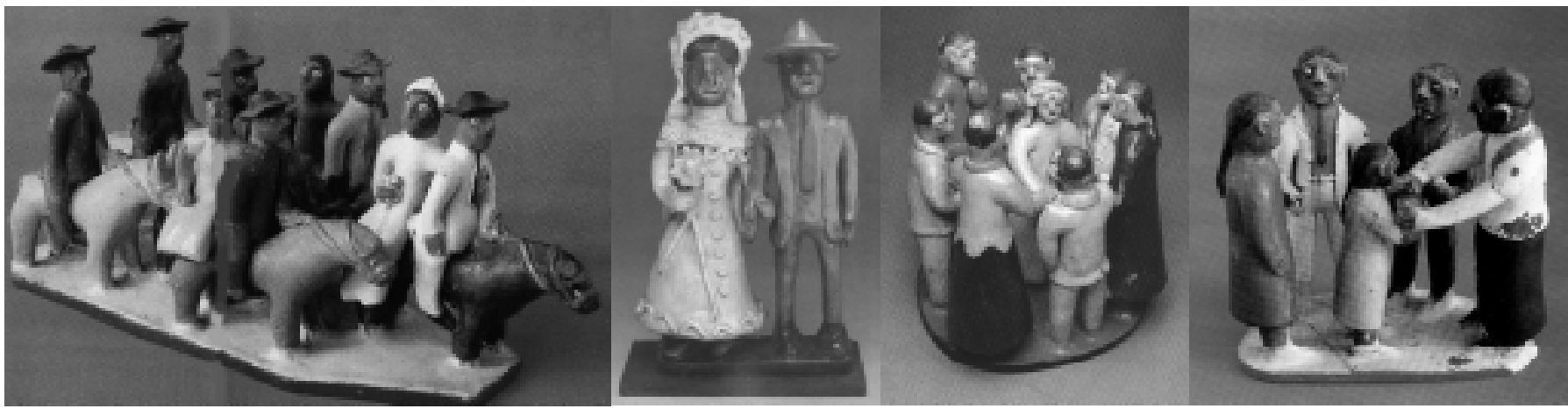

VITALINO, Casamento matuto, O noivo e a noiva, Festa de casamento, Batizado. Museu do Homem do Nordeste, Recife, PE, e Museus Raymundo Ottoni de Castro Maya, Rio de Janeiro, RJ 